\title{
ANALISIS RHODAMIN B PADA SAUS TOMAT YANG BEREDAR DI KOTA MADIUN DENGAN METODE KROMATOGRAFI LAPIS TIPIS
}

\author{
Pranita Nurdiana Agustin ${ }^{1)}$, Ani Sulistyarsi ${ }^{2}$, Sri Utami ${ }^{3)}$ \\ ${ }^{1,2,3)}$ Program Studi Pendidikan Biologi IKIP PGRI Madiun \\ Email : pranita.nurdiana@yahoo.com ${ }^{1)}$,anismasa81@yahoo.com ${ }^{2}$, sriutami31@ gmail.com ${ }^{3)}$
}

Diterima 2 Februari 2016, Disetujui 13 Maret 2016

\begin{abstract}
Rhodamin is one of additional food ingredient which often used to recolour the food. The additional food ingredient contains carsinogenic which can affect our health with a cancer as that ingredient is not acceptable ingredient for food. Unfortunately,many Indonesian do not know whether the syntetical ingredients can be used or that is being prohibited to use. The purpose of this research is not only to observe whether there is Rhodamin B inside the tomato sauces around Madiun, but also to get the result of the analysis as the mateial for aditif subtance experiment in Bio-chemical lesson. Furthermore, this descriptive qualitative research used non random sampling as its technique. The sample is taken from pentol seller, mie ayam seller and bakso seller. The samples are being analyzed with Kremtografi Lapis Tipis (KLT). The result of the analysis showed that all of the sample is negative. On the other hand, there is no Rhodamin B on it. The indicated sample has the same Rf with Rhodamin B. It will change it color into red as its response toward $\mathrm{H} 2 \mathrm{SO} 4$ and $\mathrm{HCl}$. The sample also being compared with wantex. The result showed that the Rf samples had A3, A4, A5, B4, B5,C1, C2, C3, C4 dan C5. Based on the result, the assumption of the samples is that the samples have wantex material on it
\end{abstract}

Keywords: rhodamin B, saus tomat, KLT

\section{PENDAHULUAN}

Indonesia merupakan negara gemah ripah loh jinawi, berbagai jenis tanaman dapat tumbuh di Indonesia. Tomat merupakan salah satu tanaman yang tumbuh subur di Indonesia dan mampu meningkatkan kesejahteraan masyarakat Indonesia. Berbagai olahan dari tomat telah dikembangkan oleh masyarakat. Dewi Maulida (2010) menyebutkan bahwa tomat (Lycopersicum esculentum) merupakan salah satu produk hortikultura yang berpotensi, menyehatkan dan mempunyai prospek pasar yang cukup menjanjikan.

Pengolahan tomat menjadi berbagai produk pangan menjadi salah satu pilihan untuk dapat mengkonsumsi tomat dan memperoleh manfaat dari sifat fungsional tomat terhadap kesehatan dalam jangka waktu yang cukup lama. Tomat yang diolah menjadi pasta tomat mampu menurunkan kadar gula darah. Likopen sebagai antioksidan yang terdapat didalamnya melindungi kerja pankreas dari radikal bebas sehingga pankreas dapat menghasilkan hormon insulin dengan normal. Memahami tentang manfaat tersebut banyak industri yang membuat bahan makanan olahan dari tomat seperti saus tomat. Harga tomat yang fluktuatif dan ketersediaannya di pasaran yang tidak stabil menjadikan para produsen olahan tomat terkadang melakukan segala cara agar kegiatan produksi dapat terus berlangsung seperti substitusi bahan baku, penggunaan pewarna dan pengawet sintetis dan sebagainya. 
Industri saus tomat skala kecil notabene tidak menggunakan pasta tomat atau tomat segar, tetapi hanya menggunakan esens Tomat dengan bahan pengisi Pepaya, Ubi Jalar atau tepung Tapioka. Setiap bahan yang digunakan pada pembuatan saus Tomat mempunyai fungsi tertentu yang bertujuan untuk memperbaiki rasa, warna, aroma, dan kekentalan. Gula akan memberikan rasa manis, garam akan memberikan rasa asin, cuka akan memberikan rasa asam dan sekaligus memberikan efek pengawetan karena sebagian besar mikroorganisme tidak tahan terhadap kondisi asam.

Winarno (dalam Siaka, 2009) salah satu contoh penyalahgunaan zat sintetis yang sering terjadi adalah bahan tambahan makanan baik pewarna, penyedap rasa, aroma, antioksidan, pemanis, pengawet dan pengental. Rhodamin B merupakan salah satu jenis zat aditif yang digunakan sebagi pewarna dalam industri tekstil namun masyarakat menggunakannya sebagai pewarna makanan. Pewarna kain atau wanteks banyak diperjualbelikan di toko umum dengan indeks warna 14700 merupakan jenis pewarna yang dilarang penggunaannya untuk berbagai makanan. Berdasarkan Peraturan Menteri Kesehatan Republik Indonesia Nomor :239/Men.Kes/Per/V/85 Tentang Zat Warna Tertentu Yang Dinyatakan Sebagai Bahan Berbahaya, Rhodamin B (C. I Food Red No.5) dengan indeks warna 45170 dan Ponceau SX (C. I Food Red No.1) dengan amonia 10\%, etanol teknis $96 \%$, isopropanol, amoia,etil asetat, metanol, amonium hidroksida, isobutanol, nbutanol, $\mathrm{HCl}, \mathrm{H}_{2} \mathrm{SO}_{4}$. Penelitian yang dilakukan oleh Riska dkk, (2013) menunjukkan bahwa dosis dan lama pemberian Rhodamin B pada mencit memberikan pengaruh yang nyata terhadap persentase kerusakan glomerulus. Hasil analisis histologis ginjal mencit memperlihatkan adanya tingkat kerusakan pada komponen penyusun ginjal yang meningkat seiring tingginya dosis dan lama pemberian. Kerusakan yang ditemukan berupa penyempitan ruang bowman pada glomerulus, hipertropi, nekrosis dan serosis tubulus.

Penelitian yang dilakukan oleh Rina Febrina (2013) menunjukkan bahwa Rhodamin B dengan dosis 150 ppm, 300 ppm dan 600 ppm berpengaruh signifikan, dapat memperlambat panjang siklus estrus pada mencit betina dewasa. Zat pewarna sintetis dalam makanan dapat menggangu fungsional tubuh. Berkembangnya ilmu pengetahuan dan teknologi telah menciptakan penemuan penemuan baru termasuk keberhasilan dalam bidang kimia yaitu dengan mensintesis bahan kimia baru bahan makanan yang berbahaya bagi kesehatan. Penelitian bertujuan untuk menganalisa beberapa sampel saus tomat yang digunakan oleh para pedagang di kota Madiun.

\section{METODOLOGI PENELITIAN}

Teknik analisis data dalam penelitian ini adalah deskriptif kualitatif yang dilakukan dengan observasi (M.Burhan, 2007: 78 ). Sampel yang telah terkumpul dianalisa menggunakan Kromatografi Lapis tipis kemudian menghitung Rfnya masing-masing.

Alat yang digunakan dalam penelitian ini adalah satu set alat kromatografi lapis tipis, timbangan, pemanas air, lampu UV $254 \mathrm{~nm}$ dan UV $366 \mathrm{~nm}$, dan tabung reaksi. Bahan yang digunakan dalam penelitian ini adalah saus tomat, standar Rhodamin B, wantex merah lombok (ponceau SX), benang wol, eter, akuades, asam asetat $10 \%$, amonia $2 \%$.

Penelitian dilaksanakan dalam dua tahap yaitu tahap pengambilan sampel dan tahap pengujian sampel. Pengambilan 
sampel dilakukan dengan teknik nonprobability sampling yaitu teknik yang tidak memberikan kesempatan yang sama bagi setiap unsur atau anggota populasi untuk dipilih menjadi sampel (Sugiono, 2006: 60). Sampel yang akan dianalisa diperoleh dari para pedagang yang menggunakan saus tomat. Pedagang yang menggunakan saos tomat ada beberapa namun yang diambil sebagai sampel dalam penelitian ini adalah pedagang pentol, Pedagang Bakso dan pedagang Mie Ayam yang berada di sekitar IKIP PGRI Madiun, jalan Setia Budi dan Jalan Slamet Riyadi.

Pengujian sampel dilakukan di Laboraturium SMKN 3 Kimia Madiun. Proses pengujian Sampel melalui beberapa tahapan. Tahap Pertama proses pembuatan bahan baku pembanding. Pembuatan bahan baku pembanding dilakukan dengan melarutkan 25,00 mg Rhodamin B dalam larutan etanol $96 \%$ p.a.

Tahap kedua proses pemisahan zat. Langkah yang dilakukan dalam proses pemisahan zat ialah Mencuci benang wol dengan menggunakan eter untuk menghilangkan lemak. Mendidihkan benang wol yang telah dicuci dengan eter dalam larutan $\mathrm{NaOH} 1 \%$ dan membilasnya dengan air. Kemudian merendam 10 gram sampel dalam $10 \mathrm{ml}$ amonia $2 \%$ yang telah dilarutkan dalam $70 \%$ dan direndam selama kurang lebih 12 jam. Larutan kemudian disaring dengan filtrat dan menguapkannya dengan penangas air. Larutan asam dibuat dengan mencampurkan air $10 \mathrm{ml}$ dengan $5 \mathrm{ml}$ asam asetat $10 \%$. Residu hasil filtrat yang telah diuapkan dilarutkan dalam larutan asam. Benang wol yang telah dibilas dengan air dimasukkan kedalam larutan asam kemudian mendidihkannya. Benang wol dididihkan pada larutan basa yang diperoleh dengan melarutkan $10 \mathrm{ml}$ amonia $10 \%$ dalam etanol $70 \%$ sehingga warna benang wol luruh dalam larutan basa tersebut.
Tahap ketiga ialah analisa sampel dengan Kromatografi lapis tipis. Meneteskan $2 \mu \mathrm{l}$ cuplikan pada plat KLT, kemudian mengelusi dalam bejana berisi isopropanol: amonia 100:25 v/v. Cuplikan akan bergerak dan mengalami perubahan warna dan jarak hingga mencapai batas akhir. Plat kemudian diangkat dan dikeringkan. Faktor retensi (Rf) merupakan penunjuk tingkat kepolaran suatu zat. Jika suatu Zat mempunyai Rf yang rendah maka zat tersebut mempunyai kepolaran yang tinggi. $\mathrm{Rf}$ diperoleh dengan membandingkan jarak perubahan jarak sampel dengan perubahan jarak eluennya.

$$
\mathrm{Rf}=\frac{\text { Jarak tempuh komponen }}{\text { Jarak tempuh eluen }}
$$

Nilai hRf tiap sampel dibandingkan dengan hRf Rhodamin B. Sampel yang mempunyai nilai hRf sama atau mendekati hRf Rhodamin B di indikasikan mengandunng Rhodamin B.Selain itu cuplikan sampel dipertajam dengan reaksi semprot $\mathrm{HCl}$ dan $\mathrm{H}_{2} \mathrm{SO}_{4}$. Sampel yang mengandung Rhodamin $\mathrm{B}$ akan berwarna Merah Muda dan berwarna jingga jika bereaksi dengan $\mathrm{H}_{2} \mathrm{SO}_{4}$.

\section{HASIL DAN PEMBAHASAN}

Analisis Rhodamin B pada Saus Tomat yang beredar di kota Madiun dengan metode kromatografi Lapis Tipis menunjukkan hasil yang negatif. Hasil analisa berdasarkan nilai $\mathrm{Rf}$ masing masing sampel dibandingkan dengan $\mathrm{Rf}$ standar Rhodamin B tidak menunjukkan nilai $\mathrm{Rf}$ yang sama ataupun mendekati dan tidak menunjukkan warna merah jingga ketika direaksikan dengan $\mathrm{HCl}$ dan $\mathrm{H}_{2} \mathrm{SO}_{4}$. Hasil Penelitian dapat dilihat pada gambar 1 dan tabel 1. Hasil analisa $\mathrm{Rf}$ sampel dapat dilihat pada gambar 2 .

Pada gambar 2 warna biru tua merupakan bahan baku pembanding yaitu 
Rhodamin B sedangkan warna merah hati, hijau muda, ungu dan biru muda merupakan sampel. Pada sampel A saus tomat diencerkan terlebih dahulu oleh para pedagang, sedangkan pada sampel B dan C saus masih dalam kemasan atau tidak diencerkan terlebih dahulu. Dari diagram tersebut menunjukkan bahwa baik sampel A yang diambil dari pedagang pentol tidak mengandung Rhodamin B karena tidak menunjukkan $\mathrm{Rf}$ yang sama atau mendekati Rf Rhodamin B. Sampel A terdiri dari A1, A2, A3, A4 dan A5. Sampel A2 (gambar 2a) mempunyai Rf yang paling rendah dibanding dengan $\mathrm{Rf}$ sampel yang lainnya. Pada KLT terjadi pemisahan antara senyawa-senyawa dalam suatu zat. Semakin rendah nilai Rf maka semakin tinggi kepolarannya. Sehingga sampel saus tomat yang digunakan dalam sampel A2 mempunyai kepolaran yang lebih tinggi dibanding sampel yang lainnya.

A.H. Mcheik (2013: 362) yang menguji beberapa zat dengan berbagai

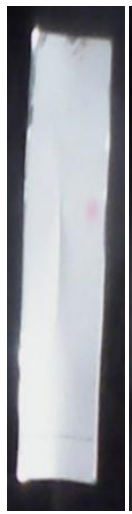

(a) konsentasi menunjukkan adanya perbedaan kecepatan atau jarak dari cuplikan sampel yang ia gunakan. Penelitian yang dilakukan oleh Pieter P.Annaert dan Kim L.R. Brouwer (2005: 390) yang menguji zat pewarna pada sandwitch dengan bahan baku pembanding Rhodamin 123 menunjukkan bahwa Rhodamin B dengan konsentrasi $1 \mu \mathrm{M}$ mencapai jarak yang lebih jauh dibandingkan dengan konsentrasi $30 \mu \mathrm{M}$ setelah di inkubasi dengan $\mathrm{Ca}^{2+}$ atau $\mathrm{Mg}^{2+}$.

Sampel B2 mempunyai Rf yang paling tinggi dibandingkan dengan yang lainnya.tersebut menunjukkan bahwa sampel B2 mempunyai kepolaran yang paling rendah dibandingkan dengan lainnya. Pada sampel B4 dan B5 mempunyai $\mathrm{Rf}$ yang hampir sama yaitu 0,898 dan 0,909. Dari $\mathrm{Rf}$ tersebut menunjukkan bahwa saus Tomat yang digunakan pada sampel tersebut sama.

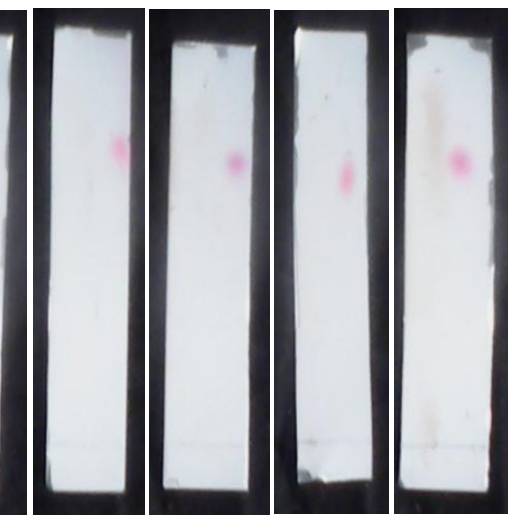
(b)
(c)
(d)
(e)
(f)
$(\mathrm{g})$
(h)

Gambar 1. Hasil Kromatogram Sampel Keterangan:
(a) A1, A2 dan Rhodamin B
(b) A3, A4 dan Rhodamin B
(c) A5, B1 dan Rhodamin B
(d) B2, B3 dan Rhodamin B
(e) B4, B5 dan Rhodamin B
(f) C1, C2 dan Rhodamin B
(g) C3, C4 dan Rhodamin B
(h) C5, pewarna kain/ wantex dan Rhodamin B

Tabel 1 Hasil Analisis dan Pengamatan Saus Tomat 
Agustin, dkk

\begin{tabular}{|c|c|c|c|c|c|c|c|c|}
\hline \multicolumn{2}{|c|}{ Rhodamin B } & \multirow[b]{2}{*}{ Sampel } & \multirow[b]{2}{*}{ hRf } & \multirow{2}{*}{$\begin{array}{c}\text { UV } \\
254 \\
\text { nm }\end{array}$} & \multirow{2}{*}{$\begin{array}{l}\text { UV } \\
366 \\
\text { nm }\end{array}$} & \multirow[b]{2}{*}{$+\mathrm{HCl}$} & \multirow[b]{2}{*}{$+\mathrm{H}_{2} \mathrm{SO}_{4}$} & \multirow[b]{2}{*}{ Simpulan } \\
\hline Warna & hRf & & & & & & & \\
\hline \multirow{2}{*}{$\begin{array}{l}\text { Merah } \\
\text { Jingga }\end{array}$} & \multirow[t]{2}{*}{0,714} & A1 & 0,623 & $\begin{array}{c}\text { Merah } \\
\text { bata }\end{array}$ & $\begin{array}{c}\text { Merah } \\
\text { bata }\end{array}$ & $\begin{array}{c}\text { Merah } \\
\text { bata }\end{array}$ & Merah bata & Negatif \\
\hline & & A2 & 0,468 & $\begin{array}{c}\text { Merah } \\
\text { bata }\end{array}$ & $\begin{array}{c}\text { Merah } \\
\text { bata }\end{array}$ & $\begin{array}{c}\text { Merah } \\
\text { bata }\end{array}$ & Merah bata & Negatif \\
\hline \multirow{2}{*}{$\begin{array}{l}\text { Merah } \\
\text { Jingga }\end{array}$} & \multirow[t]{2}{*}{0,721} & A3 & 0,849 & $\begin{array}{c}\text { Merah } \\
\text { bata }\end{array}$ & $\begin{array}{c}\text { Merah } \\
\text { bata }\end{array}$ & $\begin{array}{c}\text { Merah } \\
\text { bata }\end{array}$ & Merah bata & Negatif \\
\hline & & A4 & 0,872 & $\begin{array}{c}\text { Merah } \\
\text { bata }\end{array}$ & $\begin{array}{c}\text { Merah } \\
\text { bata }\end{array}$ & $\begin{array}{c}\text { Merah } \\
\text { bata }\end{array}$ & Merah bata & Negatif \\
\hline \multirow{2}{*}{$\begin{array}{l}\text { Merah } \\
\text { Jingga }\end{array}$} & \multirow{2}{*}{0,714} & A5 & 0,857 & $\begin{array}{c}\text { Merah } \\
\text { bata }\end{array}$ & $\begin{array}{c}\text { Merah } \\
\text { bata }\end{array}$ & $\begin{array}{c}\text { Merah } \\
\text { bata }\end{array}$ & Merah bata & Negatif \\
\hline & & B1 & 0,813 & $\begin{array}{l}\text { Merah } \\
\text { bata }\end{array}$ & $\begin{array}{c}\text { Merah } \\
\text { bata }\end{array}$ & $\begin{array}{l}\text { Merah } \\
\text { bata }\end{array}$ & Merah bata & Negatif \\
\hline \multirow{2}{*}{$\begin{array}{l}\text { Merah } \\
\text { Jingga }\end{array}$} & \multirow{2}{*}{0,761} & B2 & 0,957 & $\begin{array}{l}\text { Merah } \\
\text { bata }\end{array}$ & $\begin{array}{c}\text { Merah } \\
\text { bata }\end{array}$ & $\begin{array}{c}\text { Merah } \\
\text { bata }\end{array}$ & Merah bata & Negatif \\
\hline & & B3 & 0,674 & $\begin{array}{c}\text { Merah } \\
\text { bata }\end{array}$ & $\begin{array}{c}\text { Merah } \\
\text { bata }\end{array}$ & $\begin{array}{c}\text { Merah } \\
\text { bata }\end{array}$ & Merah bata & Negatif \\
\hline \multirow{2}{*}{$\begin{array}{l}\text { Merah } \\
\text { Jingga }\end{array}$} & \multirow[t]{2}{*}{0,761} & B4 & 0,898 & $\begin{array}{c}\text { Merah } \\
\text { bata }\end{array}$ & $\begin{array}{c}\text { Merah } \\
\text { bata }\end{array}$ & $\begin{array}{c}\text { Merah } \\
\text { bata }\end{array}$ & Merah bata & Negatif \\
\hline & & B5 & 0,909 & $\begin{array}{c}\text { Merah } \\
\text { bata }\end{array}$ & $\begin{array}{c}\text { Merah } \\
\text { bata }\end{array}$ & $\begin{array}{c}\text { Merah } \\
\text { bata }\end{array}$ & Merah bata & Negatif \\
\hline \multirow{2}{*}{$\begin{array}{l}\text { Merah } \\
\text { Jingga }\end{array}$} & \multirow{2}{*}{0,778} & $\mathrm{C} 1$ & 0,933 & $\begin{array}{c}\text { Merah } \\
\text { bata }\end{array}$ & $\begin{array}{c}\text { Merah } \\
\text { bata }\end{array}$ & $\begin{array}{c}\text { Merah } \\
\text { bata }\end{array}$ & Merah bata & Negatif \\
\hline & & $\mathrm{C} 2$ & 0,889 & $\begin{array}{c}\text { Merah } \\
\text { bata }\end{array}$ & $\begin{array}{c}\text { Merah } \\
\text { bata }\end{array}$ & $\begin{array}{c}\text { Merah } \\
\text { bata }\end{array}$ & Merah bata & Negatif \\
\hline \multirow{2}{*}{$\begin{array}{l}\text { Merah } \\
\text { Jingga }\end{array}$} & \multirow{2}{*}{0,714} & $\mathrm{C} 3$ & 0,879 & $\begin{array}{c}\text { Merah } \\
\text { bata }\end{array}$ & $\begin{array}{c}\text { Merah } \\
\text { bata }\end{array}$ & $\begin{array}{c}\text { Merah } \\
\text { bata }\end{array}$ & Merah bata & Negatif \\
\hline & & $\mathrm{C} 4$ & 0,879 & $\begin{array}{c}\text { Merah } \\
\text { bata }\end{array}$ & $\begin{array}{c}\text { Merah } \\
\text { bata }\end{array}$ & $\begin{array}{c}\text { Merah } \\
\text { bata }\end{array}$ & Merah bata & Negatif \\
\hline \multirow{2}{*}{$\begin{array}{l}\text { Merah } \\
\text { Jingga }\end{array}$} & \multirow{2}{*}{0,744} & $\mathrm{C} 5$ & 0,856 & $\begin{array}{c}\text { Merah } \\
\text { bata }\end{array}$ & $\begin{array}{c}\text { Merah } \\
\text { bata }\end{array}$ & $\begin{array}{c}\text { Merah } \\
\text { bata }\end{array}$ & Merah bata & Negatif \\
\hline & & wantex & 0,889 & $\begin{array}{l}\text { Merah } \\
\text { bata }\end{array}$ & $\begin{array}{c}\text { Merah } \\
\text { bata }\end{array}$ & $\begin{array}{l}\text { Merah } \\
\text { bata }\end{array}$ & $\begin{array}{c}\text { Merah } \\
\text { kecoklatan }\end{array}$ & Negatif \\
\hline
\end{tabular}

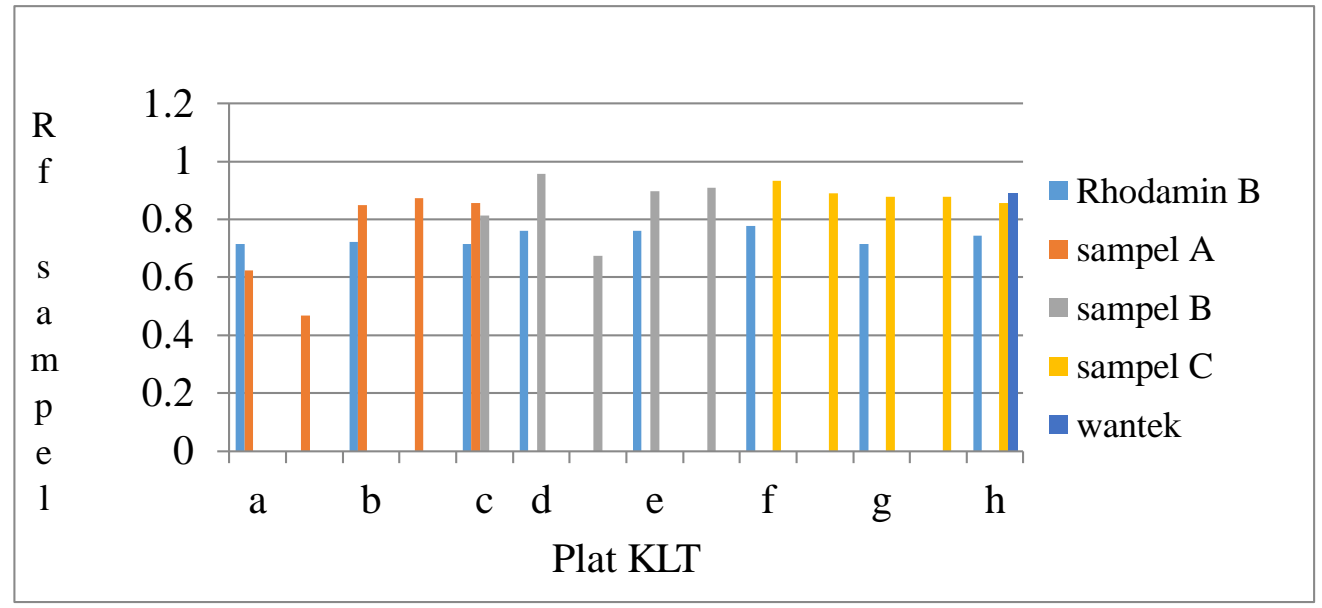

Gambar 2. Hasil Analisis Rhodamin B pada Saus Tomat

Pada sampel $\mathrm{C}$ yang diambil dari mempunyai $\mathrm{Rf}$ yang sama yaitu 0,879. pedagang bakso sampel C3 dan $\mathrm{C} 4$ Kesamaan Rf menunjukkan bahwa saus 
tomat yang digunakan pada pedagang C3 dan pedagang $\mathrm{C} 4$ adalah sama.Kepolaran suatu zat dalam sampel yang baik adalah yang mempunyai Rf sampel A1, A2 dan B3. Pada penelitian ini selain dibandingkan dengan Rhodamin B Rf sampel juga dibandingkan dengan pewarna kain/wantex warna merah lombok dengan jenis pewarna ponceau SX.

Hasil analisa menunjukkan bahwa Rf sampel ada yang sama atau hampir sama dengan $\mathrm{Rf}$ wantex sehingga sampel tersebut diduga mengandung pewarna kain /wantex warna merah lombok. Sampel tersebut adalah A3, A4, A5, B4, B5,C1, C2, C3, C4 dan C5. Sampel-sampel tersebut perlu dianalisa lebih lanjut untuk mengetahui ada tidaknya pewarna kain/wantex dengan jenis pewarna selain Rhodamin B serta kadar pewarna tersebut dalam sampel.

\section{KESIMPULAN DAN SARAN}

\section{Kesimpulan}

Pada analisa Rhodamin B pada Saus Tomat yang beredar di kota Madiun dengan metode Kromatografi lapis tipis menunjukkan hasil yang negatif, namun beberapa diduga mengandung pewarna wanteks sehingga perlu penelitian lebih lanjut.

\section{Saran}

Berdasarkan hasil yang didapatkan dari penelitian maka, dapat disarankan pada peneliti selanjutnya menganalisa wanteks pada saus tomat yang beredar di kota Madiun dan menguji cobakannya pada beberapa sampel hewan untuk mengetahui pengarunya terhadap kesehatan manusia.

\section{DAFTAR PUSTAKA}

Dewi Maulida. (2010). Ekstraksi Antioksidan ( Likopen ) Dari Buah Tomat Dengan Menggunakan
Solven Campuran, N - Heksana, Aseton, Dan Etanol. Skripsi diterbitkan. Semarang: Jurusan Kimia Universitas Diponegoro

Ilmu kimia. (2012). KLT (http://ilmu kimia.org.id diunduh 10 Maret 2014)

Mcheik, A., H \& Jamal, M., El. (2013). Journal of Chemical Technology and Metallurgy, 48, 4, 2013, 357-365: Kinetic Study Of The Discoloration Of Rhodamine B With Persulfate, Iron Activation, (online), http:// www.uctm.edu, Diunduh 18 Maret 2014)

M.Burhan Bungin. (2007). Penelitian Kualitatif komunikasi, Ekonomi, Kebijakan Publik, dan Ilmu Sosial Lainnya. Jakarta: Prenada Media Group

Peraturan Menteri Kesehatan Republik Indonesia Nomor :239/Men.Kes/Per/V/85 Tentang Zat Warna Tertentu Yang Dinyatakan Sebagai Bahan Berbahaya.

Rina Febrina dkk., (2013). Pengaruh Pemberian Rhodamin B Terhadap Siklus Estrus Mencit (Mus Musculus L.) Betina. Jurnal Biologi xvii (1) : $21-23$ (http://ojs.unud.ac.id diunduh 16 Juli 2014.

Riska Mayori dkk., (2013). Pengaruh Pemberian Rhodamin B Terhadap Struktur Histologis Ginjal Mencit Putih (Mus musculus L.) Jurnal Biologi Universitas Andalas (J. Bio. UA.) 2(1) - Maret 2013 : 43-49 (http:// jurnalsain-unand.com, diunduh 16 Juli 2014)

Siaka. (2009). Analisis Bahan Pengawet Benzoat Pada Saus Tomat Yang Beredar Di Wilayah Kota Denpasar. Jurnal Kimia, Vol.3, No. 2, (http://ojs.unud.ac.id, Diunduh 28 Februari 2014). 
Sugiono. (2006). Statistika untuk Penelitian. Bandung: Alfabeta

Yuniarti Dwi, A. (2012). Pengaruh Pemberian Jus Tomat Terhadap Kadar Glukosa Darah Pada Prediabetes. (online) (http:// eprints.undip.ac.id diunduh 18 Juni 2014). 